\title{
Correlation between interleukin-23 receptor gene polymorphisms and risk of hepatitis $B$ virus infection in patients
}

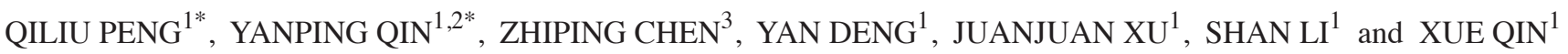 \\ ${ }^{1}$ Department of Clinical Laboratory, First Affiliated Hospital of Guangxi Medical University, \\ Nanning, Guangxi 530021; ${ }^{2}$ Department of Clinical Laboratory, Liuzhou Red Cross Hospital, \\ Liuzhou, Guangxi 54001; ${ }^{3}$ Department of Occupational Health and Environmental Health, \\ School of Public Health at Guangxi Medical University, Nanning, Guangxi 530021, P.R. China
}

Received February 16, 2013; Accepted June 24, 2013

DOI: $10.3892 / \mathrm{mmr} .2013 .1558$

\begin{abstract}
There is an increasing amount of evidence supporting the hypothesis that the pathological stage from hepatitis to hepatocellular carcinoma (HCC) is a chronic inflammatory process. Interleukin-23 (IL-23) is an important mediator and modulator of inflammation. Specific polymorphisms in the genes encoding subunits of the IL-23 receptor (IL-23R) have been consistently observed to be associated with chronic immune-mediated diseases. In the current study, these variants were hypothesized to affect the risk of hepatitis B virus infection in patients. Three polymorphisms in the $I L-23 R$ gene (rs10889677, rs1884444 and rs11465817) were examined in 84 cases of chronic hepatitis B (HBV), 67 cases of HBV-related liver cirrhosis, 89 cases of HBV-related HCC and 94 healthy controls using the polymerase chain reaction (PCR)-restriction fragment length polymorphism method and DNA sequencing. The results revealed that subjects with the TG genotype of rs1884444 appeared to have higher susceptibility to HCC compared with the TT genotype (adjusted odds ratio (OR), 2.86; 95\% confidence interval (CI), 1.39-5.85; $\mathrm{P}=0.00)$. The $\mathrm{rs} 1884444 \mathrm{G}$ allele was associated with a significantly increased risk of HCC compared with the $\mathrm{T}$ allele (adjusted OR, 1.58; 95\% CI, 0.96-2.60; $\mathrm{P}=0.07$ ).
\end{abstract}

Correspondence to: Dr Shan Li or Dr Xue Qin, Department of Clinical Laboratory, First Affiliated Hospital of Guangxi Medical University, 22 Shuangyong Road, Nanning, Guangxi 530021, P.R. China

E-mail: lis8858@126.com

E-mail: qinxue919@163.com

${ }^{*}$ Contributed equally

Abbreviations: $\mathrm{HBV}$, hepatitis $\mathrm{B}$ virus; $\mathrm{CHB}$, chronic hepatitis $\mathrm{B}$; LC, liver cirrhosis; HCC, hepatocellular carcinoma; IL-23R, interleukin-23 receptor; OR, odds ratio; 95\% CI, 95\% confidence interval; SNP, single nucleotide polymorphism; PCR, polymerase chain reaction

Key words: interleukin-23 receptor, polymorphism, chronic hepatitis B, liver cirrhosis, hepatocellular carcinoma
The rs11465817 and rs10889677 polymorphisms of the $I L-23 R$ gene were not observed as being relevant to liver disease. These observations indicate that the genetic variants in the $I L-23 R$ gene may contribute to HCC development. Additional studies with larger sample sizes must be conducted to confirm the current observations.

\section{Introduction}

Hepatocellular carcinoma (HCC) is the most common type of malignant tumor and the leading cause of cancer-related mortality in the Guangxi Zhuang Autonomous Region of China (1). Epidemiological observations have shown that hepatitis B virus (HBV) infection and exposure to aflatoxin B1 are two major etiological risk factors for the high prevalence of HCC in this area (2-3). However, only a fraction of individuals who are hepatitis B surface antigen ( $\mathrm{HBsAg}$ ) carriers and have chronic aflatoxin exposure develop HCC later in life (4). The exact mechanism of hepatocarcinogenesis is not well understood and the risk factors for $\mathrm{HCC}$ require further investigation.

Interleukin-23 (IL-23) is an inflammatory hemopoietic cytokine comprised of a heterodimer of $\mathrm{p} 40 / \mathrm{p} 19$, which shares a common p40 subunit with IL-12 (5). IL-23 is secreted predominantly by activated dendritic cells and phagocytic cells. Its main function is to induce T cells or dendritic cells to produce IL-17, IL-6 and IFN- $\gamma$. The IL-23 receptor (IL-23R) complex is comprised of IL-23R and IL-12R $\beta 1$, which is also a component of the IL-12 receptor. IL-23R is highly expressed on the surface of $\mathrm{T}$ cells, monocyte cells and natural killer $\mathrm{T}$ cells, and has been identified to be involved in several chronic inflammatory diseases (6-7). The $I L-23 R$ gene is located on chromosome $1 \mathrm{p} 31$. Polymorphisms of the $I L-23 R$ gene have been reported to be associated with susceptibility to chronic inflammatory diseases, including inflammtory bowel disease (IBD) (8-9), psoriasis (10) and multiple sclerosis (11). $I L-23 R$ gene polymorphisms have been found to be associated with gastric cancer (12-13), esophageal cancer (14), colorectal carcinoma (15) and oral cancer (16), indicating that $I L-23 R$ gene polymorphisms may represent one of the genetic factors contributing to the regulation of the IL-23 signaling pathway and thus potentially modulating susceptibility to inflam- 
Table I. Primer sequences and reaction conditions for genotyping IL-23 gene polymorphisms.

\begin{tabular}{llccl}
\hline Polymorphism & \multicolumn{1}{c}{ Primer sequence } & $\mathrm{T}_{\mathrm{a}},{ }^{\circ} \mathrm{C}$ & Restriction enzyme & Product size, bp \\
\hline rs10889677 & F: 5'-AGGGGATTGCTGGGCCATAT-3' & 61.0 & MnII & A: 216 \\
& R: 5'-TGTGCCTGTATGTGGACCA-3' & & & C: $154+62$ \\
rs1884444 & F: 5'-TCTTAGGGAAAAATGTTATGCTTTTT-3' & 56.0 & HaeIII & T: 132 \\
& R: 5'-GCATCCCATTGAATAGTGGC-3' & & & G: $106+26$ \\
rs11465817 & F: 5'-CATTAAGTAAGAGATGAAAACTTTGG-3' & 54.0 & HaeIII & A: 136 \\
& R: 5'-CTGTAGTGAGCTGTGACCATG-3' & & & C: $117+19$ \\
\hline
\end{tabular}

$\mathrm{T}_{\mathrm{a}}$, annealing temperature.

Table II. Clinical characteristics of the study population.

\begin{tabular}{|c|c|c|c|c|}
\hline Variable & Controls & CHB patients & LC patients & HCC patients \\
\hline Overall & 94 & 87 & 57 & 84 \\
\hline \multicolumn{5}{|l|}{ Gender, n (\%) } \\
\hline Male & $71(75.5)$ & $74(85.1)$ & $44(77.2)$ & $73(86.9)$ \\
\hline Female & $23(24.5)$ & $13(14.9)$ & $13(22.8)$ & $11(13.1)$ \\
\hline P-value ${ }^{a}$ & & 0.109 & 0.816 & 0.054 \\
\hline Age $(\text { years })^{\mathrm{b}}$ & $42.0 \pm 10.8$ & $40.3 \pm 11.9$ & $46.0 \pm 12.6$ & $49.5 \pm 10.3$ \\
\hline $\mathrm{P}$-value ${ }^{\mathrm{a}}$ & & 0.269 & 0.152 & 0.471 \\
\hline
\end{tabular}

${ }^{\mathrm{a} C}$ Compared with controls and ${ }^{\mathrm{b}}$ mean \pm SD. HCC, hepatocellular carcinoma; CHB, chronic hepatitis B; LC, liver cirrhosis.

matory cancers. HCC is a typical inflammation-associated malignancy and the pathological stage from hepatitis to HCC is a chronic inflammatory process (17). In the present study, a hospital-based case-control study was conducted to investigate whether $I L-23 R$ gene polymorphisms contribute to susceptibility to HBV-infected diseases in a Guangxi population in China.

\section{Materials and methods}

Study populations. The current study was designed as a retrospective study. The study consisted of 84 patients with HBV-related HCC (73 males and 11 females; mean age, 49.5 years old), 57 patients with $\mathrm{HBV}$-induced liver cirrhosis (LC; 44 males and 13 females; mean age, 46.0 years old) and 87 patients with chronic hepatitis $\mathrm{B}$ (CHB; 74 males and 13 females; mean age, 40.3 years old). Patients with HBV-related HCC had not undergone previous radiotherapy or chemotherapy. All patients with HBV-infected disease were consecutively selected from the First Affiliated Hospital of Guangxi Medical University (Guangxi, China) between January and July 2011. Control subjects were matched to the patients on the basis of age and were selected accordingly from a group of 97 control subjects ( 71 males and 23 females; mean age, 42.0 years old). Control subjects underwent a routine medical check-up in the outpatient clinic of the Department of Internal Medicine (First Affiliated Hospital of Guangxi Medical University, Guangxi, China) between January and July 2011. According to thorough clinical and laboratory evaluation, there was no personal or family history of cancer or other serious diseases observed.

Following a period of at least 6 months with elevated alanine aminotransferase or aspartate aminotransferase (>40 IU/ml), CHB was defined as positive for HBsAg. LC was diagnosed based on pathological examinations or typical morphological observations from computed tomography (CT) or ultrasonography and laboratory features. In the HCC group, newly diagnosed HCC patients were included and patients with a medical history of HCC or other cancers were excluded. Diagnosis of HBV-related HCC was based on histological or cytological findings, or on elevated serum $\alpha$-fetoprotein levels $>400 \mathrm{ng} / \mathrm{ml}$ combined with at least one positive liver image on $\mathrm{CT}$, magnetic resonance imaging or ultrasonography. All patients included were further confirmed as HBsAg-positive, HBV core antibody-positive and hepatitis B e antigen or hepatitis B e antibody-positive for at least six months. All subjects were Chinese from the Guangxi District and provided written informed consent. The study was approved by the ethics committee of the First Affiliated Hospital of Guangxi Medical University, Nanning, Guangxi, China.

Single nucleotide polymorphism (SNP) selection and genotyping. rs10889677, rs1884444 and rs11465817 were selected as candidate SNPs for determining the association between $I L-23 R$ gene polymorphisms and HBV-infected patients, as earlier studies reported positive associations of these particular SNPs with specific inflammatory diseases and types of cancer (12). Venous blood from each patient was collected 
Table III. Distribution of alleles and genotypes of three SNPs in the $I L-23 R$ gene and their association with CHB risk.

\begin{tabular}{|c|c|c|c|c|c|}
\hline Polymorphism & $\begin{array}{c}\text { CHB patients, } \\
\mathrm{n}=87(\%)\end{array}$ & $\begin{array}{l}\text { Control, } \\
\mathrm{n}=94(\%)\end{array}$ & $\begin{array}{l}\text { Crude OR } \\
(95 \% \mathrm{CI})\end{array}$ & $\begin{array}{l}\text { Adjusted OR } \\
\quad(95 \% \mathrm{CI})^{\mathrm{a}}\end{array}$ & $\begin{array}{l}\text { Adjusted } \\
\text { P-value }^{\mathrm{a}}\end{array}$ \\
\hline \multicolumn{6}{|l|}{ rs10889677 } \\
\hline \multicolumn{6}{|l|}{ Genotype } \\
\hline $\mathrm{AA}$ & $57(65.5)$ & $55(58.5)$ & 1.00 (Ref) & 1.00 (Ref) & \\
\hline $\mathrm{AC}$ & $25(28.7)$ & $34(36.2)$ & $0.71(0.38-1.34)$ & $0.74(0.39-1.40)$ & 0.35 \\
\hline $\mathrm{CC}$ & $5(5.7)$ & $5(5.3)$ & $0.97(0.27-3.52)$ & $0.93(0.25-3.40)$ & 0.91 \\
\hline \multicolumn{6}{|l|}{ Allele } \\
\hline A & 139 (79.9) & 144 (76.6) & 1.00 (Ref) & 1.00 (Ref) & \\
\hline $\mathrm{C}$ & $35(20.1)$ & $44(23.4)$ & $0.82(0.50-1.36)$ & $0.83(0.5-1.37)$ & 0.46 \\
\hline \multicolumn{6}{|l|}{ rs1884444 } \\
\hline \multicolumn{6}{|l|}{ Genotype } \\
\hline TT & $45(51.7)$ & $60(63.8)$ & 1.00 (Ref) & 1.00 (Ref) & \\
\hline $\mathrm{TG}$ & $33(37.9)$ & $24(25.5)$ & $1.83(0.95-3.52)$ & $1.82(0.93-3.53)$ & 0.08 \\
\hline GG & $9(10.3)$ & $10(10.6)$ & $1.20(0.45-3.20)$ & $1.21(0.45-3.24)$ & 0.71 \\
\hline \multicolumn{6}{|l|}{ Allele } \\
\hline $\mathrm{T}$ & $123(70.7)$ & 144 (76.6) & 1.00 (Ref) & 1.00 (Ref) & \\
\hline G & $51(29.3)$ & $44(23.4)$ & $1.36(0.85-2.17)$ & $1.34(0.83-2.14)$ & 0.23 \\
\hline \multicolumn{6}{|l|}{ rs11465817 } \\
\hline \multicolumn{6}{|l|}{ Genotype } \\
\hline AA & $34(39.1)$ & $41(43.6)$ & 1.00 (Ref) & 1.00 (Ref) & \\
\hline $\mathrm{AC}$ & $41(47.1)$ & $34(36.2)$ & $1.45(0.77-2.77)$ & $1.39(0.73-2.67)$ & 0.32 \\
\hline $\mathrm{CC}$ & $12(13.8)$ & $19(20.2)$ & $0.76(0.32-1.79)$ & $0.73(0.31-1.75)$ & 0.48 \\
\hline \multicolumn{6}{|l|}{ Allele } \\
\hline A & $109(62.4)$ & $116(61.7)$ & 1.00 (Ref) & 1.00 (Ref) & \\
\hline $\mathrm{C}$ & $65(37.4)$ & $72(38.3)$ & $0.96(0.63-1.47)$ & $0.97(0.63-1.49)$ & 0.89 \\
\hline
\end{tabular}

${ }^{a}$ Adjusted for age and gender by binary logistic regression model. HCC, hepatocellular carcinoma; OR, odds ratio; CI, confidence interval; IL-23R, interleukin-23 receptor; CHB, chronic hepatitis B; SNP, single nucleotide polymorphism.

into vacutainer tubes containing EDTA and stored at $4^{\circ} \mathrm{C}$. Amplification of the target DNA was performed by polymerase chain reaction (PCR). Primer sequences and reaction conditions are presented in Table I. The SNPs studied were genotyped by PCR-restriction fragment length polymorphism analysis. PCR products were visualized on a $2.0 \%$ agarose gel and stained with ethidium bromide (Promega Corporation, Madison, WI, USA) to detect the quality and the quantity of the amplified products. Digestion products were visualized on a 3.0\% agarose gel and stained with ethidium bromide. Direct sequencing was also performed by Sangon Biotech Company (Shanghai, China) using randomly selected subjects (10\% of all samples) to validate the method used in this study and the results were $100 \%$ concordant (Figs. 1-3).

Statistical analysis. Demographic and clinical data among groups were compared using a $\chi^{2}$ test for categorical variables and Student's t-test for continuous variables. Hardy-Weinberg equilibrium was tested with a goodness of fit $\chi^{2}$ test with one degree of freedom to compare the observed genotype frequencies among the subjects with the expected genotype frequencies. Genotype and allele frequencies of $I L-23 R$ gene polymorphisms were compared among various groups using the $\chi^{2}$ test and Fisher's exact test when appropriate, and odds ratios (OR) and
95\% confidence intervals (CIs) were calculated by binary logistic regression and adjusted for age and gender to assess the relative risk conferred by a particular allele and genotype. The linkage disequilibrium (LD) between polymorphisms was quantified using Shi's standardized coefficient D' (18). Haplotypes and their frequencies were estimated based on a Bayesian algorithm using the Phase program (19). The SPSS 13.0 software package (SPSS, Inc., Chicago, IL, USA) was used for all statistical analysis. All tests were two-tailed. $\mathrm{P}<0.05$ was considered to indicate a statistically significant difference.

\section{Results}

Clinical characteristics of the study participants. Results showed that the three candidate $I L-23 R$ genetic variants were in Hardy-Weinberg equilibrium in the patients and the control group. Demographic data of all subjects are presented in Table II. There was no statistically significant difference in age between the case and control groups. However, a significant difference was observed in gender distribution between the HCC patients and controls.

Correlation between IL-23R polymorphisms and risk of CHB. Genotype and allele frequencies of the $I L-23 R$ rs10889677, 
Table IV. Distribution of alleles and genotypes of three SNPs in the $I L-23 R$ gene and their association with LC risk.

\begin{tabular}{|c|c|c|c|c|c|}
\hline Polymorphism & $\begin{array}{c}\text { LC patients, } \\
\mathrm{n}=57(\%)\end{array}$ & $\begin{array}{l}\text { Control, } \\
\mathrm{n}=94(\%)\end{array}$ & $\begin{array}{l}\text { Crude OR } \\
(95 \% \mathrm{CI})\end{array}$ & $\begin{array}{l}\text { Adjusted OR } \\
\qquad(95 \% \mathrm{CI})^{\mathrm{a}}\end{array}$ & $\begin{array}{l}\text { Adjusted } \\
\text { P-value }^{\mathrm{a}}\end{array}$ \\
\hline \multicolumn{6}{|l|}{ rs10889677 } \\
\hline \multicolumn{6}{|l|}{ Genotype } \\
\hline $\mathrm{AA}$ & $40(70.2)$ & $55(58.5)$ & 1.00 (Ref) & 1.00 (Ref) & \\
\hline $\mathrm{AC}+\mathrm{CC}$ & $17(29.8)$ & $39(41.5)$ & $0.60(0.30-1.21)$ & $0.57(0.28-1.16)$ & 0.12 \\
\hline \multicolumn{6}{|l|}{ Allele } \\
\hline A & $97(85.1)$ & $144(76.6)$ & 1.00 (Ref) & 1.00 (Ref) & \\
\hline $\mathrm{C}$ & $17(14.9)$ & $44(23.4)$ & $0.57(0.31-1.06)$ & $0.55(0.30-1.03)$ & 0.06 \\
\hline \multicolumn{6}{|l|}{ rs1884444 } \\
\hline \multicolumn{6}{|l|}{ Genotype } \\
\hline TT & $34(59.6)$ & $60(63.8)$ & 1.00 (Ref) & 1.00 (Ref) & \\
\hline TG & $15(26.3)$ & $24(25.5)$ & $1.10(0.51-2.38)$ & $1.10(0.50-2.43)$ & 0.81 \\
\hline GG & $8(14.0)$ & $10(10.6)$ & $1.41(0.51-3.92)$ & $1.45(0.51-4.12)$ & 0.49 \\
\hline \multicolumn{6}{|l|}{ Allele } \\
\hline $\mathrm{T}$ & $83(72.8)$ & $144(76.6)$ & 1.00 (Ref) & 1.00 (Ref) & \\
\hline G & $31(27.5)$ & $44(23.4)$ & $1.22(0.72-2.08)$ & $1.21(0.70-2.08)$ & 0.50 \\
\hline \multicolumn{6}{|l|}{ rs11465817 } \\
\hline \multicolumn{6}{|l|}{ Genotype } \\
\hline AA & $16(28.1)$ & $41(43.6)$ & 1.00 (Ref) & 1.00 (Ref) & \\
\hline $\mathrm{AC}$ & $28(49.1)$ & $34(36.2)$ & $2.11(0.98-4.53)$ & $1.96(0.90-4.26)$ & 0.09 \\
\hline $\mathrm{CC}$ & $13(22.8)$ & $19(20.2)$ & $1.75(0.70-4.36)$ & $1.64(0.65-4.15)$ & 0.30 \\
\hline \multicolumn{6}{|l|}{ Allele } \\
\hline A & $60(52.6)$ & $116(61.7)$ & 1.00 (Ref) & 1.00 (Ref) & \\
\hline $\mathrm{C}$ & $54(47.4)$ & $72(38.3)$ & $1.45(0.91-2.32)$ & $1.36(0.84-2.20)$ & 0.21 \\
\hline
\end{tabular}

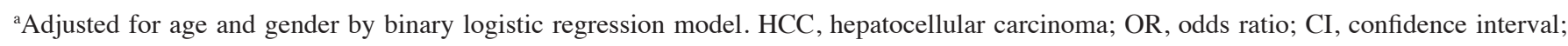
IL-23R, interleukin-23 receptor; LC, liver cirrhosis; SNP, single nucleotide polymorphism.

rs1884444 and rs11465817 polymorphisms between CHB patients and healthy controls are presented in Table III. The genotype distributions of three polymorphisms between the CHB cases and healthy controls were in Hardy-Weinberg equilibrium. No significant differences were identified between the genotype and allele frequencies of the $I L-23 R$ rs 10889677 , rs1884444 and rs11465817 polymorphisms and CHB risk. Similarily, binary logistic regression analyses adjusted for age and gender did not reveal any significant difference between $I L-23 R$ rs10889677, rs1884444 and rs11465817 polymorphisms and $\mathrm{CHB}$ risk.

Correlation between $I L-23 R$ polymorphisms and risk of $L C$ patients. Genotype and allele frequencies of the $I L-23 R$ rs10889677, rs1884444 and rs11465817 polymorphisms between LC patients and healthy controls are presented in Table IV. Genotype distributions of three polymorphisms in the LC cases and healthy controls were in Hardy-Weinberg equilibrium. No significant differences were identified between the genotype and allele frequencies of the $I L-23 R$ rs10889677, rs1884444 and rs11465817 polymorphisms and LC risk. Similarily, binary logistic regression analyses adjusted for age and gender did not show any significant difference between IL-23R rs10889677, rs1884444 and rs11465817 polymorphisms and LC risk.
Correlation between IL-23R polymorphisms and risk of $H C C$. Genotype and allele distributions of the $I L-23 R$ rs10889677, rs1884444 and rs11465817 polymorphisms between HCC patients and healthy controls are presented in Table V. The observed genotype frequencies for three variants were all in Hardy-Weinberg equilibrium in the case group and controls. Results showed no significant differences between the genotype and allele frequencies of the $I L-23 R$ rs10889677 and rs11465817 polymorphisms and HCC risk. However, in the rs1884444 polymorphism, the frequencies of the TT, TG and GG genotypes were 63.8, 25.5 and $10.6 \%$ in controls and were 45.2, 42.9 and $11.9 \%$ in case groups, respectively. The frequencies of the $\mathrm{T}$ and $\mathrm{G}$ alleles were 76.6 and $23.4 \%$ in controls, respectively and were 66.7 and $33.3 \%$ in case groups, respectively. The results indicated that there were significant differences in the genotype and allele frequencies of the $I L-23 R$ rs1884444 polymorphism between HCC patients and healthy controls. The rs 1884444 TG genotype was associated with a significantly increased risk of HCC as compared with the TT genotype (OR, 2.37; 95\% CI, 1.23-4.57; $\mathrm{P}=0.009)$. The rs1884444 $\mathrm{G}$ allele was associated with a significantly increased risk of $\mathrm{HCC}$ as compared with the $\mathrm{T}$ allele (OR, 1.64, 95\% CI, 1.03-2.61; $\mathrm{P}=0.037)$. In the binary logistic regression analysis adjusted for age and gender, the results showed that the rs1884444 TG 
Table V. Distribution of alleles and genotypes of three SNPs in the $I L-23 R$ gene and their association with HCC risk.

\begin{tabular}{|c|c|c|c|c|c|}
\hline Polymorphism & $\begin{array}{c}\text { HCC patients, } \\
n=84(\%)\end{array}$ & $\begin{array}{l}\text { Controls, } \\
\mathrm{n}=94(\%)\end{array}$ & $\begin{array}{l}\text { Crude OR } \\
(95 \% \text { CI })\end{array}$ & $\begin{array}{l}\text { Adjusted OR } \\
(95 \% \mathrm{CI})^{\mathrm{a}}\end{array}$ & $\begin{array}{l}\text { Adjusted } \\
\text { P-value }^{\mathrm{a}}\end{array}$ \\
\hline \multicolumn{6}{|l|}{ rs10889677 } \\
\hline \multicolumn{6}{|l|}{ Genotype } \\
\hline $\mathrm{AA}$ & $55(65.5)$ & $55(58.5)$ & 1.00 (Ref) & 1.00 (Ref) & \\
\hline $\mathrm{AC}$ & $26(31.0)$ & $34(36.2)$ & $0.77(0.41-1.44)$ & $0.85(0.43-1.67)$ & 0.63 \\
\hline $\mathrm{CC}$ & $3(3.6)$ & $5(5.3)$ & $0.60(0.14-2.63)$ & $0.66(0.14-3.06)$ & 0.60 \\
\hline \multicolumn{6}{|l|}{ Allele } \\
\hline A & $136(81.0)$ & $144(76.6)$ & 1.00 (Ref) & 1.00 (Ref) & \\
\hline $\mathrm{C}$ & $32(19.0)$ & $44(23.4)$ & $0.77(0.46-1.29)$ & $0.83(0.48-1.42)$ & 0.50 \\
\hline \multicolumn{6}{|l|}{ rs1884444 } \\
\hline \multicolumn{6}{|l|}{ Genotype } \\
\hline $\mathrm{TT}$ & $38(45.2)$ & $60(63.8)$ & 1.00 (Ref) & 1.00 (Ref) & \\
\hline $\mathrm{TG}$ & $36(42.9)$ & $24(25.5)$ & $2.37(1.23-4.57)$ & $2.86(1.39-5.85)$ & 0.00 \\
\hline GG & $10(11.9)$ & $10(10.6)$ & $1.58(0.60-4.15)$ & $1.24(0.43-3.51)$ & 0.69 \\
\hline \multicolumn{6}{|l|}{ Allele } \\
\hline $\mathrm{T}$ & $112(66.7)$ & $144(76.6)$ & 1.00 (Ref) & 1.00 (Ref) & \\
\hline G & $56(33.3)$ & $44(23.4)$ & $1.64(1.03-2.61)$ & $1.58(0.96-2.60)$ & 0.07 \\
\hline \multicolumn{6}{|l|}{ rs11465817 } \\
\hline \multicolumn{6}{|l|}{ Genotype } \\
\hline $\mathrm{AA}$ & $42(50.0)$ & $41(43.6)$ & 1.00 (Ref) & 1.00 (Ref) & \\
\hline $\mathrm{AC}$ & $26(31.0)$ & $34(36.2)$ & $0.75(0.38-1.46)$ & $0.72(0.34-1.50)$ & 0.38 \\
\hline $\mathrm{CC}$ & $16(19.0)$ & $19(20.2)$ & $0.82(0.37-1.82)$ & $0.99(0.42-2.31)$ & 0.97 \\
\hline \multicolumn{6}{|l|}{ Allele } \\
\hline A & $110(65.5)$ & $116(61.7)$ & 1.00 (Ref) & 1.00 (Ref) & \\
\hline $\mathrm{C}$ & $58(34.5)$ & $72(38.3)$ & $0.85(0.55-1.31)$ & $0.92(0.58-1.46)$ & 0.72 \\
\hline
\end{tabular}

${ }^{a}$ Adjusted for age and gender by binary logistic regression model. HCC, hepatocellular carcinoma; OR, odds ratio; CI, confidence interval; IL-23R, interleukin-23 receptor; SNP, single nucleotide polymorphism.

Table VI. Frequencies of the haplotypes formed by rs10889677, rs1884444 and rs11465817 SNPs in HCC patients and controls.

\begin{tabular}{|c|c|c|c|c|}
\hline Haplotype & $\begin{array}{l}\text { HCC cases, } \\
2 \mathrm{n}=168(\%)\end{array}$ & $\begin{array}{c}\text { Controls, } \\
2 \mathrm{n}=188(\%)\end{array}$ & OR $(95 \% \mathrm{CI})$ & P-value \\
\hline ATA & $69(41.1)$ & $77(41.0)$ & 1.00 (Ref) & \\
\hline ATC & $24(14.3)$ & $39(20.7)$ & $0.69(0.38-1.26)$ & 0.22 \\
\hline AGA & $25(14.9)$ & $20(10.6)$ & $1.40(0.71-2.73)$ & 0.33 \\
\hline AGC & $17(10.1)$ & $7(3.7)$ & $2.71(1.06-6.93)$ & $0.03^{\mathrm{a}}$ \\
\hline CTA & $10(6.0)$ & $13(6.9)$ & $0.86(0.35-2.08)$ & 0.74 \\
\hline CTC & $8(4.8)$ & $15(8.0)$ & $0.60(0.24-1.49)$ & 0.26 \\
\hline CGA & $7(4.2)$ & $6(3.2)$ & $1.30(0.42-4.06)$ & 0.65 \\
\hline CGC & $8(4.8)$ & $11(5.9)$ & $0.81(0.31-2.13)$ & 0.67 \\
\hline
\end{tabular}

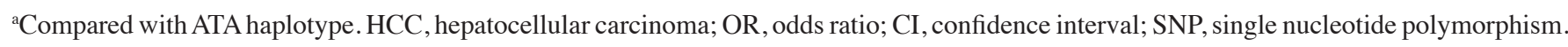

genotype was significantly associated with increased risk of HCC when compared with the TT genotype (adjusted OR, 2.86; $95 \%$ CI, 1.39-5.85; $\mathrm{P}=0.00)$. Similarily, the rs1884444 $\mathrm{G}$ allele was associated with a trend towards increased risk of HCC when compared with the T allele (adjusted OR, 1.58; 95\% CI, 0.96-2.60; $\mathrm{P}=0.07)$; however, this difference was not significant.
Haplotype analysis of IL-23R gene polymorphisms and HCC risk. Haplotype analyses were performed in HCC patients and healthy controls using the SHEsis software (18) and the possible eight haplotype frequencies are presented in Table VI. Moderate to minor LD was observed between the alleles of SNPs rs1884444 and rs11465817 (D'=0.164), rs1884444 and rs10889677 $\left(\mathrm{D}^{\prime}=0.145\right)$ and rs11465817 and rs10889677 


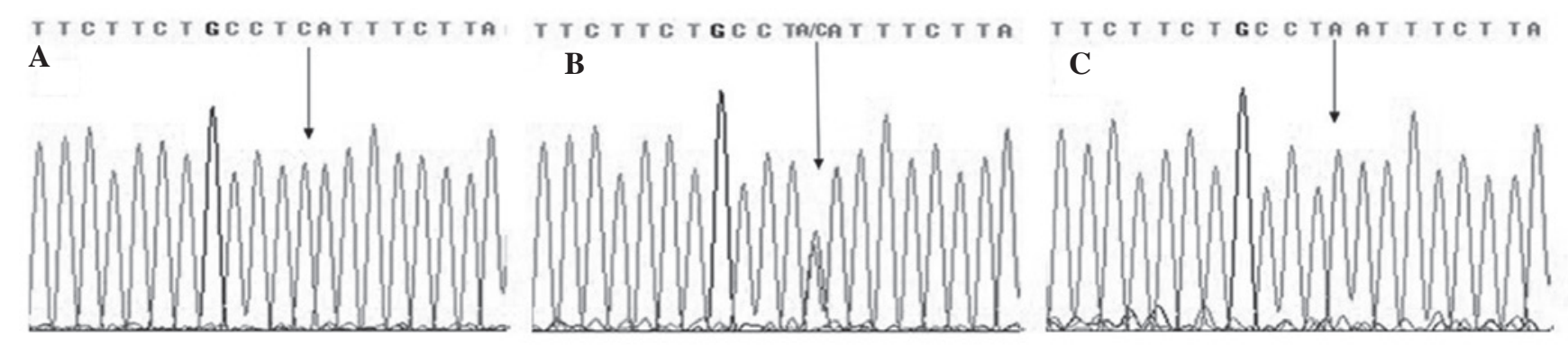

Figure 1. Sequencing map of the genotype for the $I L-23 R$ rs10889677 polymorphism. Arrow in parts A-C indicates CC, AC and AA genotypes, respectively. IL-23R, interleukin-23 receptor.
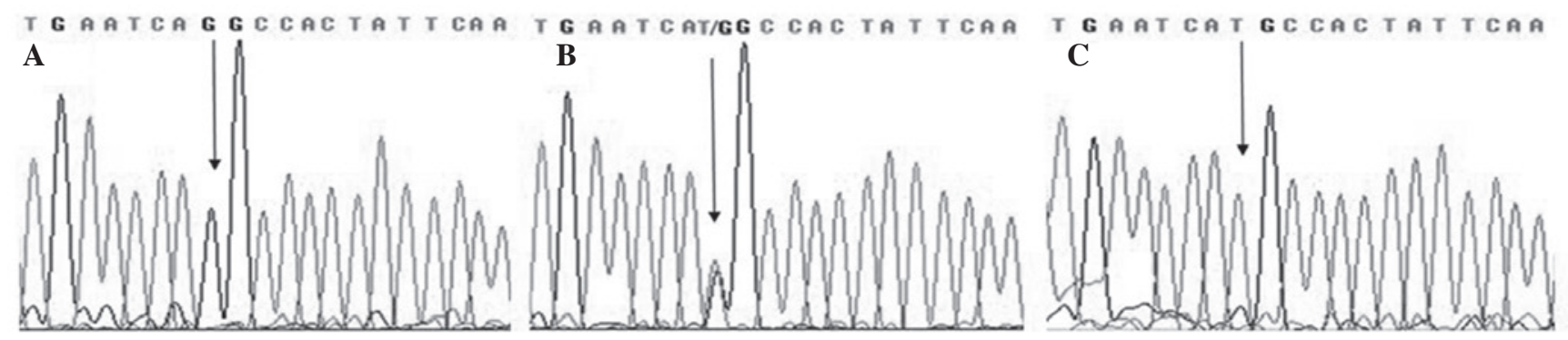

Figure 2. Sequencing map of the genotype for the $I L-23 R$ rs 1884444 polymorphism. Arrow in parts A-C indicates GG, TG and TT genotypes, respectively. $I L-23 R$, interleukin-23 receptor.
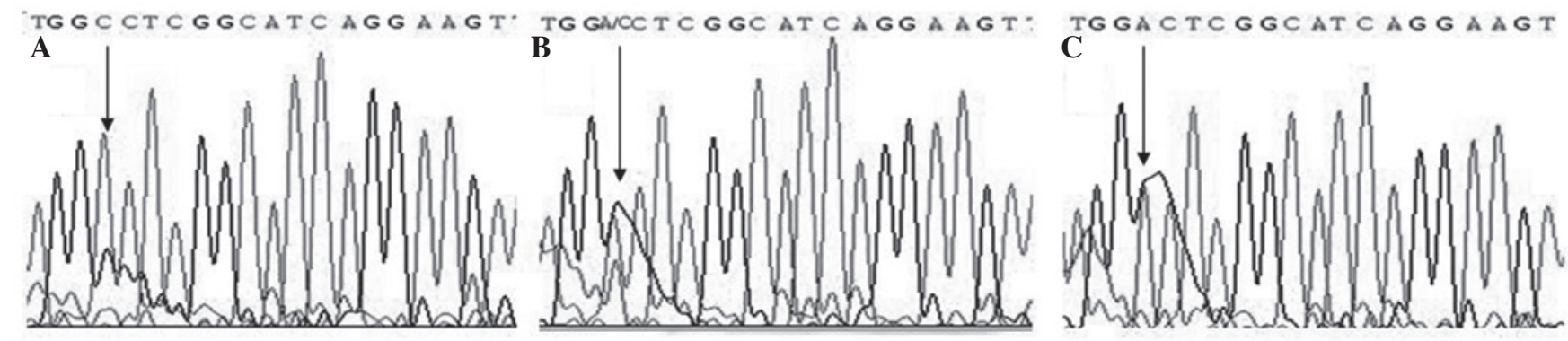

Figure 3. Sequencing map of the genotype for the $I L-23 R$ rs 11465817 polymorphism. Arrow in parts A-C indicates CC, AC and AA genotypes, respectively. $I L-23 R$, interleukin- 23 receptor.

$\left(D^{\prime}=0.230\right)$. The results showed that the major ATA haplotype accounted for 41.1 and $41.0 \%$ of these eight haplotypes in the cases and the controls, respectively. Using haplotype analyses, the AGC haplotype was observed to be associated with a significantly increased risk of $\mathrm{HCC}$ as compared with the ATA haplotype (OR, 2.71; 95\% CI, 1.06-6.93; P=0.03).

\section{Discussion}

To the best of our knowledge, this is the first study to evaluate the association between the $I L-23 R$ gene polymorphisms and HCC risk in a Guangxi population in China. IL-23R rs1884444 $\mathrm{T}>\mathrm{G}$ polymorphism was observed to be significantly associated with HCC. The rs 1884444 TG genotype was associated with a significantly increased risk of HCC compared with the rs1884444 TT genotypes (adjusted OR, 2.37; 95\% CI, 1.23-4.57; $\mathrm{P}=0.00$ ). The $\mathrm{rs} 1884444 \mathrm{G}$ allele was associated with a trend towards an increased risk effect of $\mathrm{HCC}$ as compared with the $\mathrm{T}$ allele; however, this difference was not significant (adjusted OR, 1.58; 95\% CI, 0.96-2.60; $\mathrm{P}=0.07$ ). The haplotype $\mathrm{AGC}$ was associated with a significantly increased risk of HCC as compared with the major ATA haplotype (OR, 2.71; 95\% CI, 1.06-6.93; $\mathrm{P}=0.03)$. These results indicate that the $I L-23 R$ rs $1884444 \mathrm{~T}>\mathrm{G}$ polymorphism increases HCC risk and may be used as genetic susceptibility markers for HCC.

Several epidemiological studies in diverse ethnic populations have previously been conducted and results consistent with the current study have not been observed. In the current study, the frequencies of the $\mathrm{rs} 10889677 \mathrm{C}, \mathrm{rs} 1884444 \mathrm{G}$ and rs11465817 C alleles among the healthy controls were 0.234 , 0.234 and 0.383 , respectively, and these were similar to those frequencies observed in healthy Korean and Japanese populations $(20,21)$; however, the frequencies were significantly lower than those of European Caucasians $(0.689,0.618$ and 0.725 , respectively) (22). In addition, the rs10889677 A>C, rs1884444 $\mathrm{T}>\mathrm{G}$ and rs11465817 $\mathrm{A}>\mathrm{C}$ polymorphisms were observed in moderate-to-minor LD. Major haplotype frequency of the ATA among the controls in the present study was 0.410 , which 
was significantly higher than those of a study performed in Caucasians (0.213) (23), indicating that the distribution of $I L-23 R$ gene frequencies and haplotypes may vary among ethnic groups.

HCC is a typical inflammation-related malignancy (24). In addition, increasing evidence indicates that inflammation is important in the process of hepatocarcinogenesis (25-26). IL-23 is a member of the IL-12 cytokine family that stimulates memory $\mathrm{CD}^{+} \mathrm{T}$ cells to produce interferon- $\gamma$ and to promote the development of distinctive Th17 cells (27). Studies have indicated that IL-23 may enhance the proliferation of memory $\mathrm{T}$ cells and the production of interferon- $\gamma$ by activated $\mathrm{T}$ cells (5), indicating a role for IL-23 in cell-mediated antitumor immunity. IL-23R is the initial sensor of the IL-23 signal. It is also the determinant of Th17 cell expansion and in turn, serves as an important gate for the Th17-cell-mediated autoimmune responses. Due to the biological functions of IL-23R, this molecule has been hypothesized to be involved in the development of cancer and the associated complications. In agreement with this hypothesis, mice lacking $I L-23$ p19 display resistance to endogenous tumor formation when challenged in a chemical carcinogenesis protocol (28).

The $I L-23 R$ gene is located on chromosome $1 \mathrm{p} 31$. A number of studies have been conducted to investigate the associations between $I L-23 R$ gene polymorphisms and cancer risk $(12,14,29)$. Chen et al (13) observed that the nonsynonymous SNP rs1884444 of the $I L-23 R$ gene may modify the risk of gastric cancer, particularly in intestinal types of gastric cancer. In addition, Zhang et al (29) previously indicated that $I L-23 R$ polymorphisms may be important in the susceptibility and prognosis of ovarian cancer and Chu et al (14) hypothesized that the $I L-23 R$ rs6682925 and rs1884444 variants affect esophageal cancer susceptibility through modulation of IL-23R biological activity. These results are consistent with the current data. In the current study, the rs1884444 TG genotype was associated with a significantly increased risk of HCC as compared with the TT genotype (adjusted OR, 2.37; 95\%CI, 1.23-4.57; $\mathrm{P}=0.00$ ). In the binary logistic regression analysis, $\mathrm{rs} 1884444 \mathrm{G}$ allele levels were insignificant when compared with the $\mathrm{T}$ allele (adjusted OR, $1.58 ; 95 \% \mathrm{CI}, 0.96-2.60 ; \mathrm{P}=0.07)$, which may be attributed to the fact that the limited sample size prevented the analysis from reaching a significant $\mathrm{P}$-value. The rs1884444 $\mathrm{T}>\mathrm{G}$ polymorphism is located at exon 2 of the $I L-23 R$, which is responsible for the signal peptide of $I L-23 R$ (30). Thus far, the exact biological mechanism of the variant on HCC carcinogenesis has not been elucidated. Notably, according to the web-based SNP analysis tool, PupaSuite3, the T to G base change of rs1884444 may disrupt an exonic splicing enhancer, resulting in exon skipping, malformation or transcript alternative splicing. Another possible explanation is that this polymorphism results in an amino acid change in codon 3 (His $>$ Gln) and may affect the ligand receptor binding specificity and affinity, modulating the pro-inflammatory effect by Th17 cells and may be involved in the development of HCC. However, these hypotheses are based on postulations or predictions and require confirmation by biological assays in future studies.

Haplotypes are a set of closely linked genetic markers present on one chromosome which tend to be inherited together and appear frequently in a block pattern owing to the presence of LD (31). In the current study, the AGC haplotype was observed to be significantly higher in the HCC patients than in controls when compared with the ATA haplotype $(\mathrm{P}=0.03)$. It is possible that a higher prevalence of the AGC haplotype in the $I L-23 R$ gene may modulate the expression of $I L-23 R$, resulting in downregulation of the Th17 cell-mediated immune response and escape of tumor cells from immune surveillance. The current results indicate that the GCC haplotype of $I L-23 R$ gene may play a facilitative role in the development of HCC.

In summary, the rs1884444 polymorphism of the $I L-23 R$ gene was observed to be significantly correlated with the risk of HCC. These results indicate that the $I L-23 R$ gene may contribute to an inherited predisposition to HCC. Additional studies with larger sample sizes must be performed to confirm the current observations in diverse ethnic populations.

\section{References}

1. Wang JS, Huang T, Su J, et al: Hepatocellular carcinoma and aflatoxin exposure in Zhuqing Village, Fusui County, People's Republic of China. Cancer Epidemiol Biomarkers Prev 10: 143-146, 2001.

2. Yeh FS, Yu MC, Mo CC, Luo S, Tong MJ and Henderson BE: Hepatitis B virus, aflatoxins and hepatocellular carcinoma in southern Guangxi, China. Cancer Res 49: 2506-2509, 1989.

3. Tao P, Zhi-Ming L, Tang-Wei L, et al: Associated factors in modulating aflatoxin B1-albumin adduct level in three Chinese populations. Dig Dis Sci 50: 525-532, 2005.

4. Zemel R, Issachar A and Tur-Kaspa R: The role of oncogenic viruses in the pathogenesis of hepatocellular carcinoma. Clin Liver Dis 15: 261-279, 2011.

5. Oppmann B, Lesley R, Blom B, et al: Novel p19 protein engages IL-12p40 to form a cytokine, IL-23, with biological activities similar as well as distinct from IL-12. Immunity 13: 715-725, 2000.

6. Abraham $\mathrm{C}$ and Cho J: Interleukin-23/Th17 pathways and inflammatory bowel disease. Inflamm Bowel Dis 15: 1090-1100, 2009.

7. Jiang Z, Yang P, Hou S, et al: IL-23R gene confers susceptibility to Behcet's disease in a Chinese Han population. Ann Rheum Dis 69: 1325-1328, 2010.

8. Duerr RH, Taylor KD, Brant SR, et al: A genome-wide association study identifies IL-23R as an inflammatory bowel disease gene. Science 314: 1461-1463, 2006.

9. Venegas M, Beltrán CJ, Alvarez L, et al: IL-23R Arg381Gln polymorphism in Chilean patients with inflammatory bowel disease. Eur Cytokine Netw 19: 190-195, 2008.

10. Wu Y, Lu Z, Chen Y, Xue F, Chen X and Zheng J: Replication of association between interleukin-23 receptor (IL-23R) and its ligand (IL-12B) polymorphisms and psoriasis in the Chinese Han population. Hum Immunol 71: 1255-1258, 2010.

11. Illes Z, Safrany E, Peterfalvi A, et al: 3'UTR C2370A allele of the IL-23 receptor gene is associated with relapsing-remitting multiple sclerosis. Neurosci Lett 431: 36-38, 2008.

12. Chen J, Lu Y, Zhang H, et al: A nonsynonymous polymorphism in IL23R gene is associated with risk of gastric cancer in a Chinese population. Mol Carcinog 49: 862-868, 2010.

13. Chen B, Zeng Z, Xu L, et al: IL23R +2199A/C polymorphism is associated with decreased risk of certain subtypes of gastric cancer in Chinese: a case-control study. Cancer Epidemiol 35: 165-169, 2011.

14. Chu H, Cao W, Chen W, et al: Potentially functional polymorphisms in IL-23 receptor and risk of esophageal cancer in a Chinese population. Int J Cancer 130: 1093-1097, 2012.

15. Poole EM, Curtin K, Hsu L, et al: Genetic variability in IL23R and risk of colorectal adenoma and colorectal cancer. Cancer Epidemiol 36: e104-e110, 2012.

16. Chien $\mathrm{MH}, \mathrm{Hsin} \mathrm{CH}$, Chou LS, et al: Interleukin-23 receptor polymorphism as a risk factor for oral cancer susceptibility. Head Neck 34: 551-556, 2012.

17. Martin M and Herceg Z: From hepatitis to hepatocellular carcinoma: a proposed model for cross-talk between inflammation and epigenetic mechanisms. Genome Med 4: 8, 2012. 
18. Shi YY and He L: SHEsis, a powerful software platform for analyses of linkage disequilibrium, haplotype construction and genetic association at polymorphism loci. Cell Res 15: 97-98, 2005.

19. Stephens M, Smith NJ and Donnelly P: A new statistical method for haplotype reconstruction from population data. Am J Hum Genet 68: 978-989, 2001.

20. Ban Y, Tozaki T, Taniyama M,Nakano Y, Yoneyama K, Ban Y and Hirano T: Association studies of the IL-23R gene in autoimmune thyroid disease in the Japanese population. Autoimmunity 42: 126-130, 2009.

21. Kim ES, Kim SW, Moon CM, et al: Interactions between IL17A, IL23R and STAT4 polymorphisms confer susceptibility to intestinal Behcet's disease in Korean population. Life Sci 90: 740-746, 2012

22. Faragó B, Magyari L, Sáfrány E, et al: Functional variants of interleukin-23 receptor gene confer risk for rheumatoid arthritis but not for systemic sclerosis. Ann Rheum Dis 67: 248-250, 2008

23. Ferguson LR, Han DY, Fraser AG, Huebner C, Lam WJ and Morgan AR: IL23R and IL12B SNPs and haplotypes strongly associate with Crohn's disease risk in a New Zealand population. Gastroenterol Res Pract 2010: 539461, 2010.

24. Liao R, Sun TW, Yi Y, et al: Expression of TREM-1 in hepatic stellate cells and prognostic value in hepatitis B-related hepatocellular carcinoma. Cancer Sci 103: 984-992, 2012.
25. Szabo G and Lippai D: Molecular hepatic carcinogenesis: impact of inflammation. Dig Dis 30: 243-248, 2012.

26. Qin LX: Inflammatory immune responses in tumor microenvironment and metastasis of hepatocellular carcinoma. Cancer Microenviron 5: 203-209, 2012.

27. McGeachy MJ, Chen Y, Tato CM, et al: The interleukin 23 receptor is essential for the terminal differentiation of interleukin 17-producing effector T helper cells in vivo. Nat Immunol 10: 314-324, 2009.

28. Langowski JL, Zhang X, Wu L, et al: IL-23 promotes tumour incidence and growth. Nature 442: 461-465, 2006.

29. Zhang Z, Zhou B, Zhang J, et al: Association of interleukin-23 receptor gene polymorphisms with risk of ovarian cancer. Cancer Genet Cytogenet 196: 146-152, 2010.

30. Mancini G, Kan SH and Gallagher G: A novel insertion variant of the human IL-23 receptor-alpha chain transcript. Genes Immun 9: 566-569, 2008.

31. Seng KC and Seng CK: The success of the genome-wide association approach: a brief story of a long struggle. Eur J Hum Genet 16: 554-564, 2008. 